\title{
Representações visuais da mulher afrodescendente em livros didáticos
}

\author{
Luciana Coutinho Pagliarini de Souza \\ Pós-doutora com estágio na Universität Kassel, na Alemanha, e professora do PPG em \\ Comunicação e Cultura da Universidade de Sorocaba (Uniso). \\ Email: luciana.souza@prof.uniso.br
}

\author{
Maria Ogécia Drigo \\ Doutora em Comunicação e Semiótica - PUC-SP; pós-doutoranda pela ECA-USP. Professora do \\ Programa de Pós-Graduação em Comunicação e Cultura da Universidade de Sorocaba (Uniso). \\ E-mail: maria.drigo@prof.uniso.br
}

Resumo: Este artigo apresenta resultados de uma pesquisa em desenvolvimento, sob os auspícios da Fapesp, que tem como propósito averiguar como o "outro" é visualmente representado em livros didáticos indicados pela PNLD-2011. O cabelo da mulher afrodescendente, enquanto aspecto identitário, é focalizado, a fim de verificar se os livros didáticos contribuem para difundir o discurso do "branqueamento" para o homem negro mostrado pelas mídias ou, ao contrário, contribuem para prolongar a herança cultural africana. Para tanto, reflexões sobre alteridade e construção da identidade cultural e, em seguida, a análise semiótica de representações visuais coletadas de livros didáticos são apresentadas. A preocupação com a construção de ambientes que propiciem a vivência com o outro constitui a importância deste artigo.

Palavras-chave: Comunicação e Educação; representações da mulher afrodescendente; identidade cultural; livro didático.
Abstract: This paper presents the results of an ongoing research, with the support of Fapesp, and which has as objective to investigate how the "other" is visually represented in teaching materials indicated by PNLD-2011. The hair of afro-descendant woman, as an identitary element, is the focus of the research, in order to verify if the books contribute to disseminate the "whitening" discourse about the black people which is constructed by media or, on the contrary, to contribute to extend the African cultural heritage. For this purpose, we present thoughts on the alterity and on the construction of cultural identity and, then, the semiotic analysis of visual representations collected from teaching materials. The concern with the construction of environments which allow the experience with the other constitutes the relevance of this paper.

Keywords: Communication and Education; representations of afro-descendant woman; cultural identity; teaching materials.

\section{INTRODUÇÃO}

O artigo apresenta resultados de pesquisa desenvolvida sob os auspícios da Fapesp, cujo contexto são interseções entre as áreas de Comunicação e Educação ${ }^{1}$. De um lado, a presença da imagem enquanto representação visual, estabelecendo

Recebido: 07/08/2013

Aprovado: 25/10/2013

1. Este artigo traz resultados de pesquisa desenvolvida pelas autoras, sob os auspícios da Fapesp, intitulada "Representações do outro: estudo com imagens em livros didáticos". Foi apresentado no GT de Educomunicação no XIII Ibercom ocorrido em maio de 2013, em Santiago de Compostela. 
2. SODRÉ, M. Claros e escuros: identidade, povo e mídia no Brasil. Petrópolis: Vozes, 1999.

3. Idem, op. cit., p. 256.

4. PARÂMETROS CURRICULARES NACIONAIS: TERCEIRO E QUARTO CICLOS DO ENSINO FUNDAMENTAL: LÍNGUA ESTRANGEIRA. Brasília: MEC, 1998, pp. 120-122.

5. Idem, p. 121.

6. GUIA DE LIVROS DIDÁTICOS: PNLD 2011. Brasília: Ministério da Educação, Secretaria de Educação Básica, 2010 (para todas as disciplinas escolares). Disponível em: <http:// portal.mec.gov.br/index. php?option=com_conten $\mathrm{t} \& \mathrm{view}=$ article\&id $=1238$ 9\&Itemid=1129>. Acesso em: 09 jan. 2014.

7. SANTAELLA, L. Semiótica aplicada. São Paulo: Pioneira Thomson Learning, 2002. interações e produzindo sentidos; de outro, a sua inserção no ambiente educacional via livros didáticos. Tendo a alteridade como mote, interessa-nos compreender como a mulher afrodescendente é mostrada no material pedagógico. Para tal empreita, nosso foco prende-se à questão estética da fenotipia escura, mais especificamente o cabelo, como marca simbólica e identitária a ser rastreada.

Na esteira de Sodréé, a questão do cabelo parece constituir uma espécie de índice semiótico da revalorização identitária. Não há, na verdade, novidade nessa questão, a não ser que ela tenha se tornado quase obsessiva, tal sua recorrência na mídia, sobretudo na publicidade.

Constrói-se, assim, por identificação projetiva uma identidade negra com "materiais fantasísticos" do homem branco. No espelho neoliberal (mercado e mídia), o descendente de africano tem uma espécie de "semiurgia" identitária, que o transforma em branco diferente - fenotipicamente degradé...

Diante disso, interessa-nos verificar se o tratamento dado às representações visuais da mulher negra presentes no livro didático - no caso, pelo cabelo - reproduz a identidade regida pelo paradigma branco como mecanismo discriminatório produzido pelas mídias ou se ela escapa a essas amarras ao apresentar o cabelo como continuidade de elementos culturais africanos ressignificados no Brasil, impregnado da história, memória e herança cultural africana presentes na formação cultural afro-brasileira.

No que diz respeito ao tratamento dado ao "outro", ao diferente, os Parâmetros Curriculares Nacionais (PCNs) ${ }^{4}$ revelam-se cientes da dificuldade histórica para se lidar, no Brasil, com o desconhecimento dos indivíduos sobre a heterogeneidade de seu país, o que reitera a temática da discriminação racial/ étnica, marcada pelo preconceito e pela injustiça. Por essa razão, delegam ao material didático a responsabilidade de tratar respeitosamente a pluralidade cultural, dando "ao aluno a possibilidade de conhecer o Brasil como país complexo, multifacetado e algumas vezes paradoxal" .

Para a análise das imagens, lançamos mão de quatro coleções de livros didáticos de língua portuguesa destinadas às séries finais do ensino fundamental, resenhadas no Guia de Livros Didáticos ${ }^{6}$ para adoção na escola pública. Dentre os critérios de avaliação do Guia, consta a prerrogativa de que as obras devam reconhecer as marcas identitárias dos diversos alunos brasileiros, tais como gênero, raça e classe social, entre outras, além da diversidade de contextos de ensino e aprendizagem do Brasil, prevendo a diversidade do público ao qual ele se destina.

Nesse sentido, procedimentos para interpretação de imagens seriam adequados tanto como instrumental de análise para os livros didáticos como para o professor, em forma de conhecimento pertinente à sua prática em sala de aula. Para tal, nos valemos do percurso analítico sugerido por Santaella ${ }^{7}$, que, com base nos fundamentos do signo para Peirce, centra-se nos três modos que capacitam qualquer coisa a funcionar como signo: a qualidade, o atributo de ser existente e o caráter de lei. Este método de análise semiótica faz falar o signo 
e, por permitir elaborar um inventário do potencial significativo de representações visuais, mostra-se profícuo como instrumental para nos locomovermos nesse manancial de signos.

\section{REFLEXÕES SOBRE O "OUTRO": O CABELO COMO MARCA IDENTITÁRIA}

A questão da identidade leva-nos a caminhar por um terreno movediço. $\mathrm{Na}$ esteira de $\mathrm{Hall}^{8}$, a identidade fixa, essencial e permanente já não vigora em tempos pós-modernos. O sujeito assume identidades diferentes em momentos distintos em conformidade com a maneira como os sistemas de significação e representação cultural se apresentam. São, assim, determinadas histórica, e não biologicamente.

Também Sodré sustenta que, no pensamento social da contemporaneidade, assiste-se à troca da problemática da identidade pela identificação. Afirma que a identidade pessoal "dá hoje lugar a identificações movediças (grupais, afetivas, midiáticas), suscetíveis de pôr em crise figuras das doutrinas identitárias tradi-

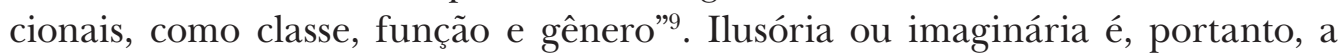
identidade, à medida que "diz respeito apenas às representações e aos objetos sobre os quais se podem fazer projeções intelectuais"10.

A identidade, seja nacional ou pessoal, segundo o mesmo autor, afirma-se primeiro como processo de diferenciação, ou seja, um processo que identifica o que é igual e o que é diferente. Em seguida, afirma-se "como um processo de integração ou organização das forças diferenciais, que distribui os diversos valores e privilegia um tipo de acento" ${ }^{11}$. A identidade entendida à luz do idem latino faz referência à igualdade ou estabilidade das representações e apresenta-se como unidade. Essa unidade, que se pretende natural, despida da representação histórica e da ficção, é responsável pelas representações racistas.

As representações identitárias do negro veiculadas pelo discurso hegemônico da sociedade brasileira reforçam-lhe o caráter primitivo, exótico; acentuam as diferenças em virtude dos traços fenotípicos. À ideia de mestiçagem ou amorenamento subjaz a noção de uma raça apta a desfazer a distância entre a pigmentação escura e o paradigma branco-europeu, capaz de representar a unidade da raça na materialização de uma "terceira raça". Sodré, contudo, avisa que

[...] falar-se de raça só é admissível como noção culturalmente (e jamais biologicamente) marcada, donde a possibilidade da "relação racial", isto é, aquela caracterizada por dissimetria nas relações hierárquicas e simbólicas entre os seres humanos em virtude de diferenças fenotípicas ${ }^{12}$.

Mas como as diferenças são apresentadas na mídia, quer jornalística, quer publicitária ou televisiva? Para Sodré, a mídia é detentora de um gênero discursivo que legitima a desigualdade social pela cor da pele, inicialmente pelo entendimento do povo como público, o que a distancia do comprometimento com causas verdadeiramente públicas ou com a afirmação da diversidade da sociedade brasileira. Organizando-se como indústria, a mídia contemporânea
8. HALL, S. A identidade cultural na pós-modernidade. Rio de Janeiro: DP\&A, 2006.

9. SODRÉ, M., op. cit., pp. 40-41.

10. Idem, p. 42.

11. Idem, p. 45.

12. Idem, p. 194. 
não tem sua atenção voltada para as causas públicas ou políticas, ao contrário, ela se pauta pelos ditames do comércio e da publicidade. Questões como preconceitos ou discriminações estão fora de ordem. São quatro os fatores que, segundo este autor, suscitam o racismo midiático: 1) a negação da existência do racismo, contribuindo, desta forma, para a reprodução do fenômeno; 2) a tendência a se recalcar aspectos identitários positivos das manifestações simbólicas de origem negra, tanto no jornalismo quanto nos vários modos de produção da indústria cultural; 3) a estigmatização da pele escura como marca da desqualificação da diferença num país de dominação branca. Parte daí qualquer forma de discriminação quer ou não consciente; e 4) a indiferença profissional, visível no número insignificante de funcionários negros na mídia brasileira, cuja maioria ocupa cargos distantes da visibilidade pública.

Ocorre que, em meados dos anos 1990, a publicidade descobre os indivíduos de pele escura como um novo filão no mercado. O efeito provocado na autoimagem e autoestima permitiu que se vislumbrasse um reposicionamento da presença da raça no mundo. Para traçar o perfil desse novo consumidor, pesquisas foram feitas e uma série de fatores ligados à cultura negra foram revelados. Uma atmosfera emocional do afrocentrismo trouxe, na esteira, a valorização estética do biotipo do negro brasileiro na mídia impressa (revistas), no cinema, na publicidade. Mas era o indivíduo negro que ascendia socialmente o foco da divulgação.

A obsessão contemporânea com o cabelo explica-se pelo fato de que o atual discurso midiático sobre o negro é mais estético do que político, doutrinário ou ético. Essa forma de construir um imaginário forjado numa identificação com padrões idealizados esconde o fato de que a diferença é sempre histórica e produzida numa relação com indivíduos e grupos hegemônicos. É sutil e astuciosa a maneira como esses padrões são impostos sem a presença de afrontamentos. O sujeito de cor se submete ao corpo ideal oferecido como modelo pela mídia. Investido desse ideário, o corpo-mídia do negro, tornado performático, reveste-se de uma fantasia étnica que mascara a desigualdade social.

Feita essa breve explanação, à luz das ideias de Sodré, busquemos na análise de algumas imagens verificar o que se depreende da sua materialidade, ou seja, a maneira como a representação afrodescendente, a partir do cabelo enquanto marca fenotípica simbólica, se desvela no livro didático.

\section{O QUE "DIZEM" AS IMAGENS...}

Das 93 ilustrações encontradas nas quatro coleções consultadas, escolhemos 62 e foi possível distribuí-las em três grupos. O primeiro grupo, composto por um total de 8 imagens, tem os cabelos cobertos como mote; o segundo, apresentando um total de 44 imagens, traz os cabelos crespos; o terceiro grupo apresenta os cabelos encaracolados num total de 10 representações visuais. Semioticamente, os cabelos aqui funcionam como índices, isto é, signos que mantêm com seu objeto uma conexão de fato, e são parte dele. Contudo, ao 
apontar para o objeto, esse índice/cabelo se impregna de dados culturais, ideológicos, de história e torna-se símbolo. Esse jogo sígnico perpassa as análises.

Apresentamos a seguir três imagens mais representativas de cada grupo e as respectivas leituras amparadas no processo de significação, objetivação e interpretação.

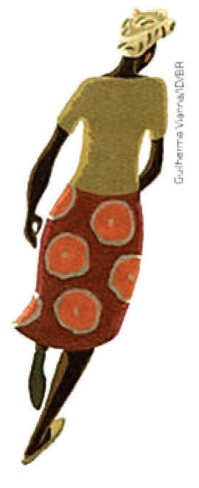

$A^{13}$
Grupo 1: Afrodescendência em cena

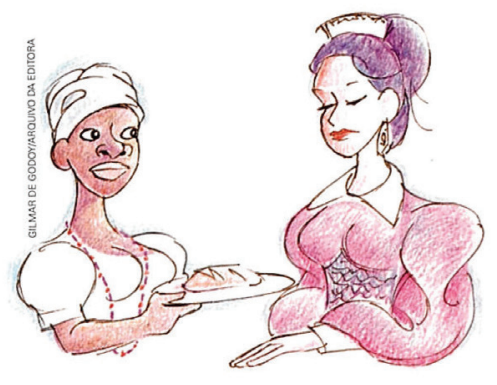

$\mathrm{B}^{14}$

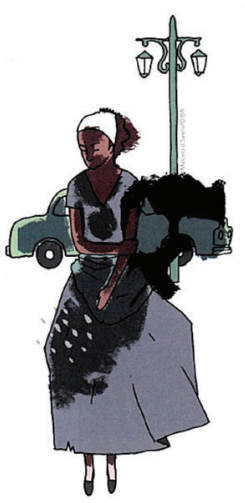

$\mathrm{C}^{15}$

A cor marrom-escura é a qualidade que se destaca na representação da pele das três figuras, e o cabelo sob o turbante ou sob o lenço é o modo como nosso objeto de análise se apresenta e produz sentidos nesse primeiro grupo. Somente na terceira figura é possível vislumbrar parte dele e perceber que se trata de um cabelo crespo, sem qualquer artifício, expressão autêntica da negritude. É o aspecto indicial que, nesse instante, aflora.

A postura de cada uma dessas mulheres negras é revelada quer pelo movimento sinuoso da primeira, que a passos leves sai de cena; quer pelo olhar servil e lábios cerrados da segunda; quer pela escuridão que envolve a terceira acentuando-lhe a solidão e a expressão de tristeza. Em comum, há o silêncio que permeia cada uma das figuras...

As qualidades (qualissignos), os signos existentes (sinsignos) revestem-se de elementos da cultura (legissignos) e vão dando corpo ao processo interpretativo. Nesse caminhar, provocam efeitos - interpretantes - do nível emocional, do nível que equivale a uma constatação (dicente) e finalmente, a um argumento, cada um deles decorrente, respectivamente, da natureza dos signos acima nomeados. No nível emocional - desalento, tristeza, desesperança, submissão -, no nível dicente, quando se constata que são mulheres que ainda trazem as marcas da escravidão e interpretantes argumentais que reconstroem a história e a cultura afro-brasileira, reproduzindo a exclusão, o preconceito, a rejeição da alteridade.

O turbante é parte importante do vestuário africano, cujo uso se distingue por diferenciar grupos culturais, sociedades religiosas ou estado civil. $\mathrm{O}$ uso desse acessório, nas circunstâncias em que as três representações visuais apresentam (Grupo 1), liga-se à servidão, ao peso da história, da memória, ao

13. MARCHETTI, G. Para viver juntos. São Paulo: Edições SM, 2011, v. 9, p. 182.

14. CAMPOS, E. Viva português. São Paulo: Ática, 2012, v. 7, p. 52.

15. MARCHETTI, G., op. cit., p. 47. 
16. SODRÉ, M., op. cit., p. 259.

17. TAGUIEFF apud SODRÉ, M., op. cit., pp. 194-195.

18. TODOROV, T. A conquista da América: a questão do outro. São Paulo: Martins Fontes, 1999, p. 223.

19. MARCHETTI, G., op. cit., p. 216.

20. FERREIRA, G., TrabaIhando com a linguagem. São Paulo: Quinteto Editorial, 2009, v. 7, p. 9.

21. CAMPOS, E., op. cit., p. 152.

22. GOMES, Nilma Lino; GOMES, NILMA LINO2003GOMES, N. L. Educação, identidade negra e formação de professores/as: um olhar sobre o corpo negro e o cabelo crespo. Educação e Pesquisa (USP), São Paulo, v. 29 , n. 1,2003 , p. 177. silêncio. É essa a ligação que os livros didáticos propiciam na apresentação dessas ilustrações: o "Outro" em posição subalterna ao "Mesmo hegemônico", segundo expressão de Sodré ${ }^{16}$. Os cabelos em ausência ou cobertos metaforizam aqui a perda da força, a abnegação. É o racismo universalista de tipo espiritualista, preconizado por Taguieff ${ }^{17}$, que se delineia: as raças evoluem e tornam-se superiores na razão direta do progresso civilizatório e que, por sua vez, dialoga com o segundo eixo dentre os três propostos por Todorov ${ }^{18}$, a saber, o que corresponde a uma ação de aproximação ou distanciamento, na qual há adoção dos valores do outro, ou submissão, ou ainda indiferença.

\section{Grupo 2: O exótico em cena}

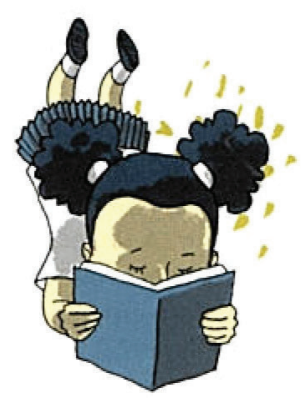

$A^{19}$

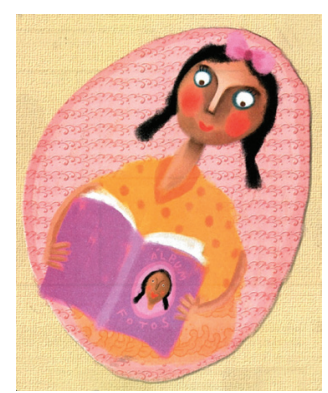

$\mathrm{B}^{20}$

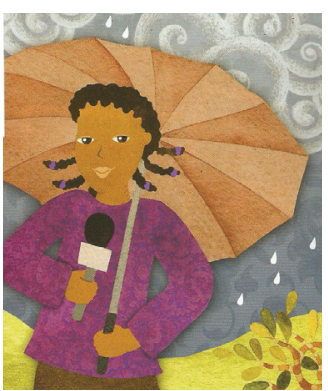

$\mathrm{C}^{21}$
Nas imagens do Grupo 2, também o marrom forte pintando a pele das três meninas-moças é a qualidade que se apreende logo de início. Além dela, outras cores fortes e alegres adornam as personagens: um azul forte pinta a capa do livro que esconde parte do rosto da menina; um cor-de-rosa vivo emoldura a segunda menina e colore suas bochechas, faz-se laço em sua cabeça e ainda, num tom mais forte, está no livro que ela tem nas mãos. Também funcionando como moldura para o rosto da jovem, uma sombrinha feita de marrom em degradê se apresenta. As imagens B e C (Grupo 2) são emolduradas pela mesma forma oval que lhes ressalta o rosto, colocando-as em evidência.

Se os cabelos vieram, anteriormente, escondidos pelo turbante ou pelo lenço, agora eles se mostram, mas não livremente... são presos, trançados, amarrados. São cabelos que as aproximam da raiz africana pelo viés de uma estética exótica. Segundo Gomes,

[...] o uso de tranças pelos negros, além de carregar toda uma simbologia originada de uma matriz africana ressignificada no Brasil, é, também, um dos primeiros penteados usados pela criança negra e privilegiados pela família. Fazer as tranças, na infância, constitui um verdadeiro ritual para essa família. Elaborar tranças variadas no cabelo das filhas é uma tarefa aprendida e desenvolvida pelas mulheres negras ${ }^{22}$.

Diferentemente das mulheres negras presentes no primeiro grupo, as do segundo grupo se apresentam inseridas num contexto de grande peso sociocultural: as duas primeiras são leitoras, a última, por estar com um microfone na mão, aparenta ser jornalista, apresentadora de TV... 
Grupo 3: O cabelo "repaginado": a mulata em cena

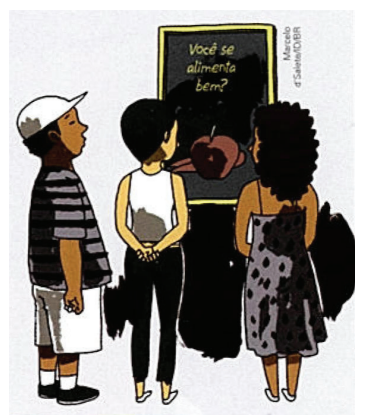

$\mathrm{A}^{23}$

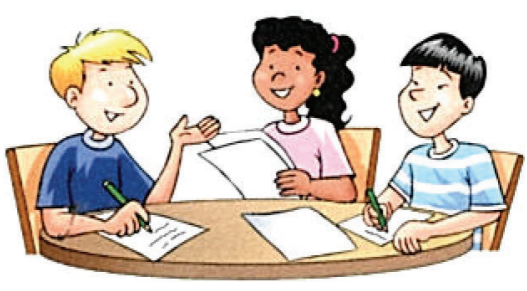

$B^{24}$

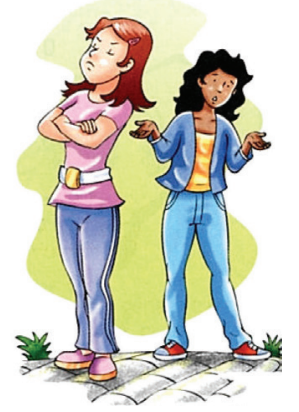

$\mathrm{C}^{25}$

No terceiro grupo, o marrom, não tão forte e vivo como nas imagens anteriores, colore a pele das meninas. Os cabelos, agora mais longos, soltos ou com penteados mais leves, são os que predominam.

Cachos firmes se depreendem do desenho do primeiro cabelo, que cai nas costas da menina. Cachos mais leves, amarrados num rabo de cavalo, enformam os cabelos da segunda menina; a terceira já tem cabelos mais longos, ondulados e mais lisos que as anteriores. Em comum, a cor preta. $\mathrm{O}$ ondulado mais liso e comprido codifica a mulata, símbolo da mestiçagem cantada no Brasil em prosa e versos, "terceira raça" que aproxima a pigmentação escura da clara e, pretensamente, diminui a distância, atenua ilusoriamente o processo discriminatório.

No âmbito do referente apresentado pelas imagens, notamos que as figuras B e C (Grupo 3), pelo fato de terem o ambiente escolar como contexto, mantêm a mesma inclusão no universo letrado que marcou as figuras do segundo grupo. Mas é a ideia de coletividade que caracteriza esse terceiro grupo.

A ideia de estar-junto afasta o estigma da exclusão, instaura o ideal de pertencimento facilitado pela proximidade estética entre os meninos e meninas representados. O "outro" se dilui nesse grupo. O ideal estético do branco funciona como revalorização identitária. O livro didático traz nessas representações visuais o que a mídia propaga como padrão e o enganoso processo de "descolonização da sensibilidade oprimida" que, na verdade, mascara a desigualdade, nega a pluralidade ou a diversidade.

\section{CONSIDERAÇÕES FINAIS}

A questão sobre como o negro é tratado nos livros didáticos, tendo o cabelo enquanto marca simbólica e identitária como foco, norteou este trabalho. Interessava-nos verificar se os livros didáticos como produção midiática faziam ecoar o mesmo discurso reprodutor da identidade do homem de cor regida pelo "branqueamento" produzido pelas outras mídias ou, o contrário, contribuíam para preservar a herança cultural africana.

Encontramos, nos 16 livros consultados, imagens que apresentavam o cabelo em diferentes nuances: o cabelo coberto que simbolizava a exclusão

23. PENTEAdO, A. E. Arruda. Para viver juntos. São Paulo: Edições SM, 2011, v. 8, p. 203.

24. TERRA, E.; CAVALLETE, F.T. Projeto Radix: raiz do conhecimento. São Paulo: Scipione, 2009, v. 6, p. 59.

25. Idem, op. cit., v. 7, p. 56. 
ancorada pela forte referência à escravidão; o cabelo crespo que valorizava o biótipo afro; e o cabelo ondulado que "passava a limpo" a negritude, fazendo vir à tona o corpo-mídia.

Ainda que essas três facetas da simbologia do cabelo tenham sido apresentadas pelo livro didático, a faceta que mais representações visuais incorporaram (44 aparições) foi a do Grupo 2: "O exótico em cena".

Neste ponto, tomamos de empréstimo o princípio da exotopia, desenvolvido por Bakhtin ${ }^{26}$. Para o autor, exotopia significa desdobramento de olhares a partir de um lugar exterior que permite que se apreenda do sujeito algo que ele não vê. Dessa forma, o outro é necessário para completar a percepção que temos de nós mesmos.

Sob esse prisma, pensamos que talvez esse olhar dirigido à exterioridade da mulher afrodescendente como o "outro" revele um tratamento respeitoso das diferenças que contribua para que os alunos/aprendizes possam vivenciar a experiência da alteridade.

\section{REFERÊNCIAS}

CAMPOS, E. et al. Viva português. São Paulo: Ática, v. 7-9, 2012.

FERREIRA, G. et al. Trabalhando com a linguagem. São Paulo: Quinteto, 2009, v. 7 .

GOMES, N. L. Educação, identidade negra e formação de professores/as: um olhar sobre o corpo negro e o cabelo crespo. Educação e Pesquisa (USP), São Paulo, v. 29, n.1, 2003.

GUIA DE LIVROS DIDÁTICOS: PNLD 2011. Brasília: Ministério da Educação, Secretaria de Educação Básica, 2010 (para todas as disciplinas escolares). Disponível em: <http://portal.mec.gov.br/index.php?option=com_content\&view $=$ article\&id=12389\&Itemid=1129>. Acesso em: 09 jan. 2014.

HALL, S. A identidade cultural na pós-modernidade. Rio de Janeiro: DP\&A, 2006.

MARCHETTI, G. et al. Para viver juntos. São Paulo: Edições SM, v. 9, 2011.

PARÂMETROS CURRICULARES NACIONAIS: TERCEIRO E QUARTO CICLOS DO ENSINO FUNDAMENTAL: LÍNGUA ESTRANGEIRA. Brasília: MEC, 1998.

PENTEADO, A. E. Arruda et al. Para viver juntos. São Paulo: Edições SM, v. 8, 2011.

SODRÉ, M. Claros e escuros: identidade, povo e mídia no Brasil. Petrópolis: Vozes, 1999.

TERRA, E.; CAVALLETE, F. T. Projeto Radix: raiz do conhecimento. São Paulo: Scipione, v. 6-7, 2009.

26. BAKHTIN, M. Estética da criação verbal. São Paulo: Martins Fontes, 2000.
TODOROV, T. A conquista da América: a questão do outro. São Paulo: Martins Fontes, 1999. 